\title{
High Expression of PPFIA1 Is Associated With Tumor Progression and a Poor Prognosis in Esophageal Squamous Cell Carcinoma
}

Hongdian Zhang

Tianjin Cancer Institute: Tianjin Tumor Hospital

Ran Jia

Tianjin Cancer Institute: Tianjin Tumor Hospital

\section{Yueyang Yang}

Tianjin Cancer Institute: Tianjin Tumor Hospital

\section{Zhilin Sui}

Tianjin Cancer Institute: Tianjin Tumor Hospital

\section{Wanyi Xiao}

Tianjin Cancer Institute: Tianjin Tumor Hospital

\section{Xianxian Wu}

Tianjin Cancer Institute: Tianjin Tumor Hospital

\section{Lei Gong}

Tianjin Cancer Institute: Tianjin Tumor Hospital

\section{Zhentao Yu}

National Cancer Center

Peng Tang ( $\boldsymbol{\sigma}$ tangpeng@tjmuch.com )

Tianjin Cancer Institute: Tianjin Tumor Hospital https://orcid.org/0000-0002-5403-0817

\section{Research article}

Keywords: Esophageal squamous cell carcinoma, PPFIA1, Bioinformatics analysis, Immunohistochemistry, Prognosis

Posted Date: May 25th, 2021

DOI: https://doi.org/10.21203/rs.3.rs-554718/v1

License: (1) (1) This work is licensed under a Creative Commons Attribution 4.0 International License. Read Full License 


\section{Abstract}

Background: PTPRF interacting protein alpha 1 (PPFIA1) is reportedly related to the occurrence and progression of several types of malignancies. However, its role in esophageal squamous cell carcinoma (ESCC) remains unknown. We aimed to investigate the expression and clinical value of PPFIA1 in ESCC.

Methods: The Oncomine, Gene Expression Profiling Enrichment Analysis (GEPIA), and Gene Expression Omnibus (GEO) databases were utilized to explore PPFIA1 mRNA expression in esophageal cancer. The associations of PPFIA1 expression with clinicopathological variables and prognosis were evaluated in the GSE53625 dataset and verified in quantitative real-time polymerase chain reaction (qRT-PCR)-based cDNA array and immunohistochemistry (IHC)-based tissue microarray (TMA) datasets. The interactions between PPFIA1 and other genes based on the protein-protein interaction (PPI) network was analyzed via the STRING website.

Results: PPFIA1 expression was obviously upregulated in ESCC tissues versus adjacent normal tissues according to online database analyses (all $P<0.05$ ). High PPFIA1 expression was significantly associated with several clinicopathological features, including tumor size, histological grade, tumor invasion depth, lymph node metastasis, and tumor-node-metastasis (TNM) stage. High PPFIA1 expression was related to worse outcomes and was identified as an independent prognostic indicator of overall survival (OS) in ESCC patients GSE53625 dataset, $P=0.004$; CDNA array dataset, $P<0.001$; TMA dataset, $P=0.039$ ). PPI analysis demonstrated that PPFIA1 was highly correlated with multiple genes, including UNC13B, RAB3A, PTPRD, and SYT1.

Conclusion: PPFIA1 may be associated with ESCC progression and could be used as a biomarker for prognostic evaluation in ESCC patients.

\section{Background}

Esophageal cancer is ranked as the eighth most common cancer and the sixth leading cause of cancerrelated death worldwide. Esophageal squamous cell carcinoma (ESCC) is the main pathological subtype, accounting for nearly $90 \%$ of esophageal cancer tumors in China [1]. Surgical resection and neoadjuvant or adjuvant therapy are the main methods for ESCC treatment. Despite advances in diagnosis and therapy, recurrence and metastasis are common, which significantly decreases the overall survival (OS) of patients. Therefore, there is an urgent need to identify the metastatic mechanisms of ESCC and to explore effective indicators for early diagnosis, prognosis prediction, and treatment response.

PTPRF interacting protein alpha 1 (PPFIA1) is a member of the LAR protein-tyrosine phosphataseinteracting protein family of cytosolic scaffold proteins [2]. Several studies have reported that PPFIA1 is abnormally expressed, plays a vital role in invasion and metastasis, and may be used as a potential prognostic molecular marker for several types of malignancies, including breast cancer, laryngeal cancer, oral squamous cell carcinoma, colon cancer and ovarian cancer [3-8]. However, the expression of PPFIA1 and its correlation with clinicopathological features and patient prognosis in ESCC remain uncertain. 
In the present research, we first investigated the expression of PPFIA1 in ESCC tissues and paracancerous tissues using available online datasets from the Oncomine, Gene Expression Profiling Interactive Analysis (GEPIA), and Gene Expression Omnibus (GEO) databases. The associations of PPFIA1 expression with the clinicopathological features and outcomes of ESCC patients were analyzed in the GSE53625 dataset and further confirmed in the CDNA array and tissue microarray (TMA) datasets.

\section{Methods}

\section{Bioinformatics analyses}

The following websites and datasets were used:

\section{GEPIA}

The difference in the expression of PPFIA1 mRNA and its relationship with OS in human tumors was analyzed through the GEPIA website (http://gepia.cancer-pku.cn/detail.php), which contains RNA sequencing and expression information from data from The Cancer Genome Atlas (TCGA) and the Genotype-Tissue Expression (GTEx) databases [9]. The mRNA expression levels of PPFIA1 in both tumor tissues and adjacent normal tissues are displayed in a bar chart.

\section{Oncomine}

Oncomine (http://www.oncomine.org) is a public online microarray database and comprehensive data mining platform that can be used to mine cancer genetic information [10]. The expression of PPFIA1 in esophageal cancer tissues and paracancerous tissues was analyzed through Oncomine. The data analysis was carried out based on standardized normalization techniques with statistical calculations supplied by the Oncomine website.

\section{The GEO database}

The GEO database is a publicly available database of gene expression data that stores a large amount of microarray data (https://www.ncbi.nlm.nih.gov/geo/) [11]. Six datasets from the GEO database (GSE23400, GSE20347, GSE29001, GSE53625, GSE45670 and GSE26886) were used to determine PPFIA1 mRNA expression in ESCC and normal tissues. The GEO datasets were analyzed online through GEO2R.

Furthermore, the RNA sequencing data, all clinicopathological variable data and the survival data of 179 ESCC patients were also downloaded from the GSE53625 dataset (https://portal.gdc.cancer.gov/). There were $146(81.6 \%)$ males and 33 (18.4\%) females, with a median age of 60 (range, 36 82) years. According to the criteria of the American Joint Committee on Cancer (AJCC) tumor-node-metastasis (TNM) staging system, 10 (5.6\%), 77 (43.0\%), and 92 (51.4\%) cases were considered stage I, II, and III, respectively. The OS rates at 1,3 , and 5 years were $77.1 \%, 48.6 \%$, and $40.8 \%$, respectively, with a median survival time of 42 months. 


\section{Kaplan-Meier plotter}

Kaplan-Meier Plotter (www.kmplot.com) is an online database containing survival information (including recurrence-free survival [RFS], progression-free survival [PFS], time to first progression [FP], OS, postprogression survival [PPS], or distant metastasis-free survival [DMFS]) for patients with breast, ovarian, lung or gastric cancers. The expression of PPFIA1 in cancer samples was divided into two groups (low vs. high expression) based on the automatically selected best cutoff values, and the correlation between PPFIA1 mRNA expression and patient survival was analyzed using a Kaplan-Meier survival plot with the log-rank test.

\section{The Search Tool for the Retrieval of Interacting Genes (STRING)}

We further used the STRING website (http://string-db.org/) to explore the interactions between PPFIA1 and other genes based on the protein-protein interaction (PPI) network.

\section{Tissue cDNA array data based on quantitative real-time polymerase chain reaction (qRT-PCR)}

An ESCC cDNA microarray with patient diagnosis information was purchased from Shanghai Outdo Biotech Co., Ltd. (Cat. No.: cDNA-HEsoS095Su01; Shanghai, China); the array contained samples from 67 cancer tissues and 28 adjacent esophageal tissues. These tissues were all from patients who were histologically confirmed to have ESCC and underwent esophagectomy. There were 48 males and 19 females, with a median age of 59 (range, 37 78) years. The study was approved by the Medical Ethics Committee of the Shanghai Outdo Biotech Company.

Total RNA was isolated using TRIzol reagent (Takara, Dalian, China) according to the manufacturer's instructions. cDNA was then synthesized using the SuperScript ${ }^{\mathrm{TM}}$ II Reverse Transcriptase kit (Thermo Fisher Scientific, Waltham, MA, USA) following the manufacturer's protocol. Then, $2 \mu \mathrm{l}$ cDNA was used as a template for qRT-PCR with SYBR ${ }^{\circledR}$ Premix Ex Taq ${ }^{\text {TM }}$ II (Takara, Dalian, China), and $\beta$-actin was used as the internal control. The primer sequences used were as follows: PPFIA1, forward 5'-

CTTAACCCAGGGGAAGTTACAC-3' and reverse 5'-ATCCTAAGAGACCGCTCATGC-3'; and $\beta$-actin, forward 5'GAAGAGCTACGAGCTGCCTGA-3' and reverse 5'-CAGACAGCACTGTGTTGGCG-3'. An ABI 7500 Fast RealTime PCR System (Applied Biosystems, CA, USA) was used for qRT-PCR analysis. The expression foldchanges were quantified by the $2^{-\Delta \Delta C T}$ method.

\section{TMA data based on immunohistochemical analysis}

TMAs were used for immunohistochemical staining to examine the expression of PPFIA1 protein. TMAs containing samples from 147 ESCC tissues and 40 adjacent normal esophageal tissues were made by Shanghai Outdo Biotech Co. Ltd. All paraffin block specimens were obtained from patients who underwent radical esophagectomy between 2009 and 2010 at Tianjin Medical University Cancer Institute and Hospital, with reliable information on survival. No patients had received any chemotherapy or radiotherapy before surgery. Among the patients, there were 119 males and 28 females with a median age of 68 years old. All patients were followed up until September 2016 with a median follow-up period 
of 36 months. The research protocol was approved by the Research Ethics Committee of Tianjin Medical University Cancer Institute and Hospital, and written informed consent was obtained from all patients in accordance with the principles of the Declaration of Helsinki.

The protein expression of PPFIA1 in ESCC samples was detected through IHC. In brief, the tissue sections were deparaffinized, rehydrated and incubated with an antigen retrieval solution. The activity of endogenous peroxidase was blocked with $0.3 \% \mathrm{H} 2 \mathrm{O} 2$ and $5 \%$ goat serum. Then, the sections were incubated with an anti-PPFIA1 polyclonal antibody (1:100; Cat No. DF12102) at $4{ }^{\circ} \mathrm{C}$ overnight and then incubated with a biotinylated secondary antibody for $20 \mathrm{~min}$ at room temperature based on the reagent instructions. Diaminobenzidine was used as a chromogen. The stained slide was scanned using an automatic slice scanning system.

Two or three experienced pathologists who were blind to the clinicopathological information independently performed the staining evaluation based on the staining intensity (no staining, 0; weak, 1; moderate, 2 ; strong, 3$)$ and the percentage $(0 \%, 0 ; 1 \sim 25 \%$ positive, $1 ; 26 \% \sim 50 \%$ positive, $2 ; 51 \% \sim 75 \%$ positive, $3 ; 76 \% \sim 100 \%$ positive, 4 ) of positively stained tumor cells. The immunoreactivity score was calculated as the product of the staining intensity and staining percentage scores, with the final score ranging from 0 to 12. Patients with a total score of $<4$ were considered to have low expression $(n=47)$, and those with a total score of $\geq 4$ were considered to have high expression $(n=100)$.

\section{Statistical analyses}

All statistical analyses were performed using SPSS 17.0 software (SPSS, Inc., Chicago, IL) and GraphPad Prism 7.0 software (GraphPad, Inc., La Jolla, CA, USA). Statistical differences of the Oncomine and GEPIA data were indicated automatically by the program. Differences in PPFIA1 mRNA expression between tumor tissues and adjacent normal tissues were compared using a t test. The patients were divided into two groups according to the best cutoff value of PPFIA1 expression for predicting OS calculated with the X-tile 3.6.1 software (Yale University, New Haven, CT, USA) for analysis of the GSE53625 dataset [12] or according to the median value of PPFIA1 expression for analysis of the CDNA array dataset. The chisquare test or Fisher's exact test was used for the analysis of PPFIA1 expression and clinicopathological variables. Survival analysis was carried out through the Kaplan-Meier method, and differences were assessed via the log-rank test. Univariate and multivariate Cox proportional hazards regression analyses were performed to further evaluate the independent prognostic variables. The correlations between PPFIA1 expression and the expression of other genes were assessed by Pearson's correlation analysis. A $P$-value $<0.05$ was deemed statistically significant.

\section{Results}

\section{The expression of PPFIA1 mRNA in various tumor tissues}

We first examined the expression level of PPFIA1 mRNA in various tumors with the GEPIA website, and the results showed significantly higher PPFIA1 expression in several types of tumor tissues, including 
esophageal cancer (ESCA), pancreatic adenocarcinoma (PAAD), and thymoma tissues, compared with adjacent normal tissues at the RNA level (Fig. 1A). The overview of PPFIA1 expression in various tumor specimens and its detailed expression in ESCA specimens, as well as in normal controls, were further analyzed with the Oncomine database. PPFIA1 mRNA expression was obviously increased in the tumor tissues versus normal tissues from most of the datasets for all types of tumors (Fig. 1B). The fold changes in PPFIA1 mRNA expression in different ESCA tissues of 7 datasets are displayed in Supplementary Table $\mathbf{S 1 .}$

\section{The expression of PPFIA1 was upregulated in ESCC tissues}

The expression of PPFIA1 mRNA was markedly higher in ESCC tumor samples than in adjacent normal samples according to the GEPIA website (Fig. 2A). This finding was further verified using the data from six GEO datasets; the results indicated that the relative PPFIA1 mRNA expression was obviously upregulated in ESCC tissues compared with paired or unpaired adjacent normal tissues in the GSE23400 ( $9.6 \pm 1.1$ vs. $8.4 \pm 0.6, P<0.001$, Fig. $2 \mathrm{~B})$, GSE20347 (10.3 \pm 1.3 vs. $8.4 \pm 0.2, P<0.001$, Fig. $2 \mathrm{C}$ ), GSE29001 (6395. $6 \pm 4748.9$ vs. $1498.6 \pm 337.9, P=0.005$, Fig. 2 D), GSE53625 (12.6 \pm 1.2 vs. $11.0 \pm 0.5, P$ $<0.001$, Fig. $2 \mathrm{E})$, GSE45670 (251.5 \pm 185.9 vs. $97.5 \pm 49.6, P=0.015$, Fig. $2 \mathrm{~F})$ and GSE26886 (1.3 \pm 1.4 vs. $0.1 \pm 1.1, P=0.022$, Fig. $2 \mathrm{G}$ ) datasets.

In addition, the increased expression of PPFIA1 mRNA in ESCC samples was further confirmed through the analysis of cDNA array data based on qRT-PCR $(0.12 \pm 0.15$ vs. $0.06 \pm 0.08, P=0.003$, Fig. $2 \mathrm{H})$.

\section{Correlations between PPFIA1 mRNA expression and clinicopathological variables in ESCC patients}

The associations of PPFIA1 mRNA expression with the clinicopathological features of patients with ESCC were investigated in the GSE53625 dataset and CDNA array dataset. In the GSE53625 dataset, the 179 ESCC patients were divided into a low-expression group $(n=155)$ and a high-expression group $(n=24)$ according to the X-tile cutoff. Our results showed that high PPFIA1 expression was positively related to tumor invasion depth $(P=0.019)$, lymph node metastasis $(P=0.013)$, and TNM stage $(P=0.012)$, but no correlations were found between PPFIA1 expression and sex, age, smoking use, alcohol use, tumor location, or histological grade $(P>0.005)$ (Table 1$)$. 
Table 1

Associations of PPFIA1 mRNA expression with clinicopathological variables of 179 ESCC patients from the GSE53626 dataset.

\begin{tabular}{|c|c|c|c|c|c|}
\hline \multirow[t]{2}{*}{ Clinicopathological variables } & \multirow[t]{2}{*}{ Number } & \multicolumn{2}{|c|}{ PPFIA1 expression } & \multirow[t]{2}{*}{$x^{2}$} & \multirow[t]{2}{*}{$P$ value } \\
\hline & & Low & High & & \\
\hline Gender & & & & 0.649 & 0.420 \\
\hline Male & 146 & 125 & 21 & & \\
\hline Female & 33 & 30 & 3 & & \\
\hline Age(years) & & & & 0.316 & 0.574 \\
\hline$\leq 60$ & 99 & 87 & 12 & & \\
\hline$₫ 60$ & 80 & 68 & 12 & & \\
\hline Smoking use & & & & 2.872 & 0.090 \\
\hline No & 65 & 60 & 5 & & \\
\hline Yes & 114 & 95 & 19 & & \\
\hline Alcohol use & & & & 0.637 & 0.425 \\
\hline No & 73 & 65 & 8 & & \\
\hline Yes & 106 & 90 & 16 & & \\
\hline Tumor Location & & & & 0.771 & 0.680 \\
\hline Upper & 20 & 16 & 4 & & \\
\hline Middle & 97 & 85 & 12 & & \\
\hline Lower & 62 & 54 & 8 & & \\
\hline Histological grade & & & & 1.557 & 0.459 \\
\hline I & 32 & 29 & 3 & & \\
\hline II & 98 & 86 & 12 & & \\
\hline III & 49 & 40 & 9 & & \\
\hline Tumor invasion depth & & & & 7.935 & 0.019 \\
\hline T1- T2 & 39 & 38 & 1 & & \\
\hline T3 & 110 & 94 & 16 & & \\
\hline T4 & 30 & 23 & 7 & & \\
\hline Lymph node metastasis & & & & 10.840 & 0.013 \\
\hline
\end{tabular}




\begin{tabular}{|llllll|}
\hline Clinicopathological variables & Number & \multicolumn{2}{l}{ PPFIA1 expression } & \multirow{2}{*}{$x^{2}$} & Pvalue \\
\cline { 2 - 4 } & & Low & High & & \\
\hline N0 & 83 & 76 & 7 & & \\
\hline N1 & 62 & 56 & 6 & & \\
\hline N2 & 22 & 15 & 7 & & \\
\hline N3 & 12 & 8 & 4 & & 0.012 \\
\hline TNM stage & & & & 8.878 & \\
\hline I & 10 & 10 & 0 & & \\
\hline II & 77 & 72 & 5 & & \\
\hline III & 92 & 73 & 19 & & \\
\hline
\end{tabular}

We then analyzed PPFIA1 levels in the CDNA array of 68 ESCC patients. The patients were split into a lowexpression group $(n=34)$ and a high-expression group $(n=33)$ based on the median value of relative PPFIA1 expression. We found that PPFIA1 mRNA expression was significantly correlated with histological grade ( $P=0.031$, Supplementary Table S2). Overall, the above data indicate that the expression of PPFIA1 is associated with various important clinicopathological features of ESCC.

\section{Relationships between PPFIA1 protein expression and clinicopathological variables in ESCC patients in the TMA dataset}

We further assessed PPFIA1 protein expression using an IHC staining-based TMA containing samples from 147 surgically removed cancer tissues and 40 normal esophageal tissues. PPFIA1 was primarily localized to the cytoplasm and nucleus of cancer cells, and the expression rate was significantly higher in cancer tissues than in normal tissues $(68.0 \%$ vs. $25.0 \%, P<0.05)$. Representative images of low or high PPFIA1 expression are shown in Fig. 3. All patients were divided into the PPFIA1 low-expressing group (n $=47$ ) or the high-expressing group $(n=100)$. We further analyzed the association between PPFIA1 expression and clinicopathological variables and found that PPFIA1 expression was inversely associated with tumor location $(P=0.011)$, tumor invasion depth $(P=0.041)$, lymph node metastasis $(P=0.020)$, and TNM stage $(P=0.007)$ in ESCC patients. No significant relationships with other variables were found (all $P>0.05)$ (Table 2). 
Table 2

Correlations between PPFIA1 protein expression and clinicopathological variables in 151 patients with ESCC from the TMA dataset.

\begin{tabular}{|c|c|c|c|c|c|}
\hline \multirow[t]{2}{*}{ Clinicopathological Variables } & \multirow[t]{2}{*}{ Number } & \multicolumn{2}{|c|}{ PPFIA1 expression } & \multirow[t]{2}{*}{$x^{2}$} & \multirow[t]{2}{*}{$P$ value } \\
\hline & & Low & High & & \\
\hline Gender & & & & 0.000 & 0.983 \\
\hline Male & 119 & $38(31.9 \%)$ & $81(68.1 \%)$ & & \\
\hline Female & 28 & $9(32.1 \%)$ & $19(67.9 \%)$ & & \\
\hline Age(years) & & & & 1.433 & 0.231 \\
\hline$\leq 68$ & 77 & $28(36.4 \%)$ & $49(63.6 \%)$ & & \\
\hline$₫ 68$ & 70 & $19(27.1 \%)$ & $51(72.9 \%)$ & & \\
\hline Smoking use & & & & 0.804 & 0.370 \\
\hline No & 51 & $14(27.5 \%)$ & $37(72.5 \%)$ & & \\
\hline Yes & 104 & $36(34.6 \%)$ & $68(65.4 \%)$ & & \\
\hline Tumor Location & & & & 9.067 & 0.011 \\
\hline Upper & 6 & $0(0)$ & $6(100.0 \%)$ & & \\
\hline Middle & 123 & $37(30.1 \%)$ & $86(69.9 \%)$ & & \\
\hline Lower & 18 & $10(55.6 \%)$ & $8(44.4 \%)$ & & \\
\hline Tumor size $(\mathrm{cm})$ & & & & 0.803 & 0.370 \\
\hline$<3.5$ & 61 & $22(36.1 \%)$ & $39(63.9 \%)$ & & \\
\hline$\geq 3.5$ & 86 & $25(29.1 \%)$ & $61(70.9 \%)$ & & \\
\hline Histological grade & & & & 1.565 & 0.457 \\
\hline I & 11 & $5(45.5 \%)$ & $6(54.5 \%)$ & & \\
\hline II & 115 & $37(32.2 \%)$ & $78(67.8 \%)$ & & \\
\hline III & 21 & $5(23.8 \%)$ & $16(76.2 \%)$ & & \\
\hline Tumor invasion depth & & & & 6.369 & 0.041 \\
\hline T1- T2 & 22 & $11(50.0 \%)$ & $11(50.0 \%)$ & & \\
\hline T3 & 80 & $27(33.8 \%)$ & $53(66.3 \%)$ & & \\
\hline T4 & 45 & $9(20.0 \% \%)$ & $36(80.0 \%)$ & & \\
\hline Lymph node metastasis & & & & 5.449 & 0.020 \\
\hline
\end{tabular}




\begin{tabular}{|llllll|}
\hline Clinicopathological Variables & Number & \multicolumn{2}{l}{ PPFIA1 expression } & \multirow{2}{*}{$x^{2}$} & \multirow{2}{*}{ Pvalue } \\
\cline { 3 - 5 } & & Low & High & & \\
\hline N0 & 86 & $34(39.5 \%)$ & $52(60.5 \%)$ & \\
\hline N+ & 61 & $13(21.3 \%)$ & $48(78.7 \%)$ & & \\
\hline TNM stage & & & & 7.344 & 0.007 \\
\hline I/II & 55 & $25(45.5 \%)$ & $30(54.5 \%)$ & & \\
\hline III & 92 & $22(23.9 \% \%)$ & $70(76.1 \%)$ & & \\
\hline
\end{tabular}

\section{Increased PPFIA1 expression indicates a poorer prognosis for patients with malignancies}

In view of the high expression of PPFIA1 mRNA in a variety of malignancies, including breast, ovarian, lung, and gastric cancers, we further investigated the prognostic value of PPFIA1 through the KaplanMeier plotter website. Patients were grouped based on the automatically selected best cutoff value for PPFIA1 expression. As shown in Fig. 4, high expression of PPFIA1 apparently correlated with the RFS, OS, PPS, DMFS of patients with breast cancer (Fig. 4A, P<0.05), the PFS, OS, and PPS of patients with ovarian cancer (Fig. 4B, P< 0.05), the FP, OS, and PPS of patients with lung cancer (Fig. 4C, P<0.05), and the FP, OS, and PPS of patients with gastric cancer (Fig. 4D, P<0.05). These results suggest that high expression of PPFIA1 is obviously associated with worse outcomes in patients with breast cancer, ovarian cancer, lung cancer, and gastric cancer.

\section{Correlations between PPFIA1 expression and the prognosis of ESCC patients}

Survival analyses revealed that ESCC patients with high PPFIA1 mRNA levels had a significantly worse 5year OS rate than those with low PPFIA1 mRNA levels in the GSE53625 dataset (45.2\% vs. $12.5 \%, P<$ 0.001 , Fig. $5 \mathrm{~A})$ and $\mathrm{CDNA}$ array dataset $(38.0 \%$ vs. $9.2 \%, P=0.001$, Fig. $5 \mathrm{~B})$. High PPFIA1 expression at the protein level was also obviously related to poor outcomes in patients in the TMA dataset (5-year OS rate: $46.0 \%$ vs. $23.4 \%, P<0.001$, Fig. 5 C).

The prognosis-related indicators in the 3 datasets were analyzed by univariate and multivariate survival analyses, and the results are presented in Table 3. In the GSE53625 dataset, age, histological grade, lymph node metastasis, and PPFIA1 expression were significantly related to OS. In the CDNA array dataset, lymph node metastasis, M status, TNM stage and PPFIA1 expression were related to OS. Moreover, age, tumor size, histological grade, tumor invasion depth, lymph node metastasis, and PPFIA1 expression were significantly related to OS in the TMA dataset. Furthermore, PPFIA1 was identified as an independent indicator of poor OS in the multivariate Cox proportional hazard regression analysis of all 3 datasets (GSE53625 dataset, $\mathrm{HR}=2.097, P=0.004$; CDNA array dataset, $\mathrm{HR}=3.464, P<0.001$; TMA dataset, $H R=1.596, P=0.039)$. Other independent factors included age (GSE53625 dataset), tumor size 
(TMA dataset), lymph node metastasis (GSE53625, TMA datasets), and TNM stage (cDNA array dataset) (Table 3). 
Table 3

Univariate and multivariate analyses of the OS of ESCC patients in the GSE53625, CDNA array and TMA datasets.

\begin{tabular}{|c|c|c|c|c|}
\hline \multirow[t]{2}{*}{ Variable } & \multicolumn{2}{|c|}{ Univariate analysis } & \multicolumn{2}{|l|}{ Multivariate analysis } \\
\hline & $\mathrm{HR}(95 \% \mathrm{Cl})$ & $P$ value & $\mathrm{HR}(95 \% \mathrm{Cl})$ & $P$ value \\
\hline \multicolumn{5}{|l|}{ GSE53625 dataset } \\
\hline Gender & $\begin{array}{l}0.789(0.493 \sim \\
1.262)\end{array}$ & 0.323 & & \\
\hline Age & $\begin{array}{l}1.702(1.162 \sim \\
2.494)\end{array}$ & 0.006 & $1.547(1.050 \sim 2.279)$ & 0.027 \\
\hline Smoking use & $\begin{array}{l}0.737(0.500 \sim \\
1.087)\end{array}$ & 0.124 & & \\
\hline Alcohol use & $\begin{array}{l}0.873(0.594 \sim \\
1.282)\end{array}$ & 0.487 & & \\
\hline Tumor location & $\begin{array}{l}0.807(0.595 \sim \\
1.094)\end{array}$ & 0.167 & & \\
\hline Histological grade & $\begin{array}{l}1.370(1.015 \sim \\
1.850)\end{array}$ & 0.040 & $1.225(0.906 \sim 1.658)$ & 0.188 \\
\hline Tumor invasion depth & $\begin{array}{l}1.260(0.919 \sim \\
1.726)\end{array}$ & 0.151 & & \\
\hline $\begin{array}{l}\text { Lymph node } \\
\text { metastasis }\end{array}$ & $\begin{array}{l}1.434(1.178 \sim \\
1.735)\end{array}$ & 0.000 & $1.318(1.069 \sim 1.623)$ & 0.010 \\
\hline PPFIA1 expression & $\begin{array}{l}2.635(1.627 \sim \\
4.267)\end{array}$ & 0.000 & $2.097(1.270 \sim 3.465)$ & 0.004 \\
\hline \multicolumn{5}{|l|}{ cDNA array } \\
\hline Gender & $\begin{array}{l}0.650(0.350 \sim \\
1.207)\end{array}$ & 0.173 & & \\
\hline Age & $\begin{array}{l}1.346(0.781 \sim \\
2.321)\end{array}$ & 0.284 & & \\
\hline Histological grade & $\begin{array}{l}1.332(0.627 \sim \\
2.832)\end{array}$ & 0.456 & & \\
\hline Tumor invasion depth & $\begin{array}{l}1.281(0.662 \sim \\
2.476)\end{array}$ & 0.462 & & \\
\hline $\begin{array}{l}\text { Lymph node } \\
\text { metastasis }\end{array}$ & $\begin{array}{l}1.909(1.090 \sim \\
3.345)\end{array}$ & 0.024 & $0.401(0.130 \sim 1.233)$ & 0.111 \\
\hline M status & $\begin{array}{l}2.974(1.167 \sim \\
7.577)\end{array}$ & 0.022 & $2.500(0.874 \sim 7.155)$ & 0.088 \\
\hline
\end{tabular}




\begin{tabular}{|c|c|c|c|c|}
\hline \multirow[t]{2}{*}{ Variable } & \multicolumn{2}{|l|}{ Univariate analysis } & \multicolumn{2}{|l|}{ Multivariate analysis } \\
\hline & $\mathrm{HR}(95 \% \mathrm{Cl})$ & $P$ value & $\mathrm{HR}(95 \% \mathrm{Cl})$ & $P$ value \\
\hline TNM stage & $\begin{array}{l}2.475(1.361 \sim \\
4.499)\end{array}$ & 0.003 & $\begin{array}{l}4.952(1.519 \sim \\
16.144)\end{array}$ & 0.008 \\
\hline PPFIA1 expression & $\begin{array}{l}2.456(1.404 \sim \\
4.297)\end{array}$ & 0.003 & $3.464(1.776 \sim 6.755)$ & 0.000 \\
\hline \multicolumn{5}{|l|}{ TMA dataset } \\
\hline Gender & $\begin{array}{l}0.789(0.493 \sim \\
1.262)\end{array}$ & 0.323 & & \\
\hline Age & $\begin{array}{l}1.702(1.162 \sim \\
2.494)\end{array}$ & 0.006 & $1.340(0.906 \sim 1.982)$ & 0.143 \\
\hline Smoking use & $\begin{array}{l}1.408(0.922 \sim \\
2.150)\end{array}$ & 0.113 & & \\
\hline Tumor location & $\begin{array}{l}0.859(0.540 \sim \\
1.367)\end{array}$ & 0.522 & & \\
\hline Tumor size & $\begin{array}{l}1.632(1.096 \sim \\
2.431)\end{array}$ & 0.016 & $1.564(1.041 \sim 2.352)$ & 0.031 \\
\hline Histological grade & $\begin{array}{l}1.560(1.019 \sim \\
2.389)\end{array}$ & 0.041 & $1.536(0.981 \sim 2.406)$ & 0.061 \\
\hline Tumor invasion depth & $\begin{array}{l}1.457(1.085 \sim \\
1.956)\end{array}$ & 0.012 & $1.319(0.966 \sim 1.801)$ & 0.081 \\
\hline $\begin{array}{l}\text { Lymph node } \\
\text { metastasis }\end{array}$ & $\begin{array}{l}1.917(1.306 \sim \\
2.813)\end{array}$ & 0.001 & 1.559 (1.054 2.307) & 0.026 \\
\hline PPFIA1 expression & $\begin{array}{l}1.963(1.271 \sim \\
3.031)\end{array}$ & 0.002 & $1.596(1.021 \sim 2.494)$ & 0.039 \\
\hline
\end{tabular}

\section{Network analysis of PPFIA1 and interacting genes}

The interactions between PPFIA1 and other genes based on the protein-protein interaction (PPI) networks was analyzed via the Search Tool for the Retrieval of Interacting Genes/Proteins (STRING) website. The results showed some known and predicted interactions between PPFIA1 and UNC13B, RAB3A, PTPRD, SYT1, RIMS1, PTPRS, APBA1, PTPRF, LIN7A, and CASK. Most of these genes have been reported as oncogenes or tumor suppressor genes.

We further analyzed the associations of PPFIA1 mRNA expression with the abovementioned genes in the GSE53625 dataset. Our results showed that PPFIA1 expression was clearly correlated with UNC13B, RAB3A, PTPRD, SYT1, RIMS1, PTPRS, APBA1, PTPRF, and LIN7A expression (Figure 6B-J) but not with CASK expression (Figure 6K). 


\section{Discussion}

Early invasion and metastasis are two of the main reasons for the poor prognosis of patients with ESCC [13]. In our current study, we observed an increase in PPFIA1 expression in ESCC, which was associated with malignant biological behavior and a poorer prognosis. PPFIA1 may be a potential molecular indicator for diagnosis and prognosis evaluation and could be regarded as a new therapeutic target for ESCC.

PPFIA1 is a gene located at the $11 \mathrm{q} 13$ amplification region and mainly encodes the liprin-a1 protein in humans. It was initially discovered to control the formation and function of synapses in neurons [14]. Studies have indicated that PPFIA1 is a key regulator of cell motility, focal adhesion, cell signal transduction, and cytoskeletal organization $[8,15]$. PPFIA1 is frequently amplified and plays a crucial role in cell migration and invasion by affecting cell motility, mediating extracellular matrix degradation and facilitating the formation of lamellipodial protrusions of cancer cells [3, 16-19]. Although the role of PPFIA1 in tumor cell progression has been well verified, it is not clear whether its dysregulation is related to metastasis risk or prognosis in ESCC patients.

To determine the clinical value of PPFIA1 in ESCC, we analyzed the difference in the expression of this novel marker in tumor tissues compared with normal tissues and assessed its correlation with the survival of ESCC patients using multiple datasets. Analysis of datasets from Oncomine, GEPIA and GEO confirmed that PPFIA1 mRNA expression was markedly higher in ESCC tissues than in adjacent normal control tissues, which was further confirmed with CDNA array data based on qRT-PCR and TMA data based on IHC. These results indicated that PPFIA1 may play a vital role during the tumorigenesis of ESCC, which was consistent with the results discovered in other malignant tumors $[17,20]$. Further correlation analysis revealed that PPFIA1 expression is highly correlated with aggressive biological behaviors of tumors, indicating the important function of PPFIA1 in the progression of ESCC. It is worth mentioning that the expression of PPFIA1 was only correlated with the degree of tumor differentiation in the cDNA chip dataset, which might be due to the limited sample size in the research.

Kaplan-Meier Plotter is an online database containing survival information for patients with several types of tumors. Importantly, we discovered that PPFIA1 can be applied for the prognostic assessment of breast cancer, ovarian cancer, lung cancer and gastric cancer by online analysis. Cho et al [21]. explored the prognostic value of PPFIA1 alone or in combination with TMEM16A and FADD in patients with invasive ductal breast carcinoma, and they found that the combined expression was significantly associated with perineural invasion and a low disease-free survival rate. A recent study showed that the expression of PPFIA1 is closely related to poor response to endocrine treatment in luminal breast cancer [22]. Since PPFIA1 was found to be involved in the development of ESCC, we believe that PPFIA1 is likely to have a great impact on the survival of patients with ESCC. To obtain a reliable conclusion, we used the GSE53625, cDNA array and TMA datasets to investigate the prognostic value of PPFIA1 in ESCC. Our results indicated that high PPFIA1 expression was evidently correlated with a poorer prognosis. Notably, PPFIA1 was identified as an independent indicator of poor prognosis in all three independent databases 
in the multivariate analyses. Thus, we propose that PPFIA1 may serve as a potential diagnostic and novel prognostic biomarker, as well as a new therapeutic target for ESCC.

Mechanistically, Shen et al. confirmed that PPFIA1 enhances the proliferation and migration ability of colon carcinoma cells by interacting with the tumor suppressor protein ING4 [8]. Astro et al. suggested that liprin-a1 can determine the polarization and morphological dynamics related to cell migration by forming a complex with the liprin- $\beta 1$, ERC1/ELKS, and LL5 proteins [23]. To examine the potential mechanisms of PPFIA1 in ESCC progression, we further used the PPI network and Pearson's correlation analysis to identify proteins that may bind to PPFIA1; we identified UNC13B, RAB3A, PTPRD, SYT1 and RIMS1 as potential candidates. Some of these interacting genes have already been reported as tumor oncogenes or suppressor genes [24-26]. For instance, RAB3A interacting protein (Rab3IP) is a Rabspecific GEF, and the activation of Rab proteins, including Rab3A and Rab8, has been considered a tumorspecific marker in colorectal cancer, gastric cancer, and pancreatic cancer [27-29]. A recent study reported by Ren et al. showed that Rab3IP interacts with SSX2 and enhances an invasive aggressive phenotype of gastric cancer through epithelial-mesenchymal transition [25]. PTPRT is a phosphatase that can participate in JAK/STAT signal transduction. Deleterious mutations or copy number loss of PTPRT and its related gene PTPRD are potential markers for evaluating the resistance to bevacizumab regimens and are closely associated with shorter PFS in metastatic colorectal cancer patients [24]. However, the biological function and underlying mechanism of PPFIA1 in ESCC need to be further studied [25].

There are several certain limitations to the current study that should be pointed out. First, although the results were analyzed through bioinformatics analysis and three independent databases (GSE53625, cDNA array and TMA), the sample size involved in our study was relatively small. Second, the clinicopathological information from the three datasets was not comprehensive, and part of the information in the CDNA array dataset was incomplete. Third, the exact biological function and detailed molecular mechanism of PPFIA1 in ESCC were not verified in in vitro and in vivo experiments. Therefore, our results need to be further verified in a large patient cohort with complete clinical pathological data concerning tumor progression and prognosis.

\section{Conclusion}

In conclusion, this preliminary study indicates that the expression of PPFIA1 is significantly increased and is related to some malignant clinical features and poor outcomes in ESCC patients. PPFIA1 might be a valuable biomarker for early detection, treatment formulation and prognosis evaluation for ESCC.

\section{Abbreviations}

PPFIA1: PTPRF interacting protein alpha 1; ESCC: esophageal squamous cell carcinoma; GEO: Gene Expression Omnibus; TMA: tissue microarray; GEPIA: Gene Expression Profiling Interactive Analysis; TCGA: The Cancer Genome Atlas; GTEx: the Genotype-Tissue Expression; AJCC: the American Joint Committee on Cancer; TNM: tumor-node-metastasis; RFS: recurrence-free survival; PFS: progression-free 
survival; FP: time to first progression; PPS: postprogression survival; DMFS: distant metastasis-free survival; STRING: Search Tool for the Retrieval of Interacting Genes; PPI: protein-protein interaction; qRTPCR: quantitative real-time polymerase chain reaction; ESCA: esophageal cancer; PAAD: pancreatic adenocarcinoma.

\section{Declarations}

\section{Acknowledgements}

Not Applicable

\section{Authors contributions}

HDZ, RJ, ZTY and PT conceived and designed the workflow. YYY, ZLS, WYX and XXW performed the experiments and analyzed the data. HDZ and RJ wrote the manuscript. LG, ZTY and PT made substantial contributions to the conception of the work and substantively revised it. All authors approved the final manuscript.

\section{Funding}

This work was supported by the National Natural Science Foundation of China $(82002551,81772619)$, Clinical Trial Project of Tianjin Medical University (2017kylc006), Bethune Charitable FoundationExcelsior Surgical Fund (HZB-20190528-18), and Science and Technology Project of Tianjin Municipal Health Commission (RC20119), which only provided funding support and did not participate in specific research.

\section{Availability of data and materials}

All data generated or analyzed during this study are included in this published article and its supplementary information files.

\section{Competing Interests}

The authors declare no conflicts of interest.

\section{Ethics approval}

This study was performed with the approval of the Research Ethics Committee of Tianjin Medical University Cancer Institute and Hospital.

\section{Informed consent}

Informed consent was acquired from all patients of primary cohort for the acquisition of clinical and pathological information and the use of surgical specimens 
Consent for publication The approvals from all authors are gained for its submission

\section{References}

1. Abnet CC, Arnold M, Wei WQ. Epidemiology of Esophageal Squamous Cell Carcinoma. Gastroenterology. 2018;154:360-73.

2. Pehkonen $\mathrm{H}$, von Nandelstadh P, Karhemo PR, Lepikhova T, Grenman R, Lehti K, Monni O. Liprin-a1 is a regulator of vimentin intermediate filament network in the cancer cell adhesion machinery. Sci Rep. 2016;6:24486.

3. Astro V, Asperti C, Cangi MG, Doglioni C, de Curtis I. Liprin-a1 regulates breast cancer cell invasion by affecting cell motility, invadopodia and extracellular matrix degradation. Oncogene. 2011;30:1841-9.

4. Blessmann M, Al-Dam A, Hanken H, Assaf AT, Riecke B, Klatt J, Simon R, Sauter G, Heiland M, Kluwe $L$, Gröbe A. Amplification of the PPFIA1 gene region on 11q13 in oral squamous cell carcinomas (OSCC). J Craniomaxillofac Surg. 2013;41:845-9.

5. Brown LA, Kalloger SE, Miller MA, leM S, McKinney SE, Santos JL, Swenerton K, Spellman PT, Gray J, Gilks CB, Huntsman DG. Amplification of 11q13 in ovarian carcinoma. Genes Chromosomes Cancer. 2008;47:481-9.

6. Chiaretti S, Astro V, Chiricozzi E, de Curtis I. Effects of the scaffold proteins liprin- $\alpha 1, \beta 1$ and $\beta 2$ on invasion by breast cancer cells. Biol Cell. 2016;108:65-75.

7. Järvinen AK, Autio R, Haapa-Paananen S, Wolf M, Saarela M, Grénman R, Leivo I, Kallioniemi $O$, Mäkitie AA, Monni O. Identification of target genes in laryngeal squamous cell carcinoma by highresolution copy number and gene expression microarray analyses. Oncogene. 2006;25:6997-7008.

8. Shen JC, Unoki M, Ythier D, Duperray A, Varticovski L, Kumamoto K, Pedeux R, Harris CC. Inhibitor of growth 4 suppresses cell spreading and cell migration by interacting with a novel binding partner, liprin alpha1. Cancer Res. 2007;67:2552-8.

9. Tang Z, Li C, Kang B, Gao G, Li C, Zhang Z. GEPIA: a web server for cancer and normal gene expression profiling and interactive analyses. Nucleic Acids Res. 2017;45:W98-98W102.

10. Rhodes DR, Kalyana-Sundaram S, Mahavisno V, Varambally R, Yu J, Briggs BB, Barrette TR, Anstet MJ, Kincead-Beal C, Kulkarni P, Varambally S, Ghosh D, Chinnaiyan AM. Oncomine 3.0: genes, pathways, and networks in a collection of 18,000 cancer gene expression profiles. Neoplasia. 2007;9:166-80.

11. Yu-Jing T, Wen-Jing T, Biao T. Integrated Analysis of Hub Genes and Pathways In Esophageal Carcinoma Based on NCBI's Gene Expression Omnibus (GEO) Database: A Bioinformatics Analysis. Med Sci Monit. 2020;26:e923934.

12. Camp RL, Dolled-Filhart M, Rimm DL. X-tile: a new bio-informatics tool for biomarker assessment and outcome-based cut-point optimization. Clin Cancer Res. 2004;10:7252-9.

13. Zhang J, Luo A, Huang F, Gong T, Liu Z. SERPINE2 promotes esophageal squamous cell carcinoma metastasis by activating BMP4. Cancer Lett. 2020;469:390-8. 
14. de Curtis I. Function of liprins in cell motility. Exp Cell Res. 2011;317:1-8.

15. Dancau AM, Wuth L, Waschow M, Holst F, Krohn A, Choschzick M, Terracciano L, Politis S, Kurtz S, Lebeau A, Friedrichs K, Wencke K, Monni O, Simon R. PPFIA1 and CCND1 are frequently coamplified in breast cancer. Genes Chromosomes Cancer. 2010;49:1-8.

16. Asperti C, Astro V, Totaro A, Paris S, de Curtis I. Liprin-alpha1 promotes cell spreading on the extracellular matrix by affecting the distribution of activated integrins. J Cell Sci. 2009;122:3225-32.

17. Chiaretti S, de Curtis I. Role of Liprins in the Regulation of Tumor Cell Motility and Invasion. Curr Cancer Drug Targets. 2016;16:238-48.

18. Nagano M, Hoshino D, Koshikawa N, Akizawa T, Seiki M. Turnover of focal adhesions and cancer cell migration. Int J Cell Biol. 2012;2012:310616.

19. Yang J, Wu NN, Huang DJ, Luo YC, Huang JZ, He HY, Lu HL, Song WL. PPFIA1 is upregulated in liver metastasis of breast cancer and is a potential poor prognostic indicator of metastatic relapse.

Tumour Biol. 2017;39:1010428317713492.

20. Barros-Filho MC, Reis-Rosa LA, Hatakeyama M, Marchi FA, Chulam T, Scapulatempo-Neto C, Nicolau UR, Carvalho AL, Pinto C, Drigo SA, Kowalski LP, Rogatto SR. Oncogenic drivers in 11q13 associated with prognosis and response to therapy in advanced oropharyngeal carcinomas. Oral Oncol. 2018;83:81-90.

21. Choi EJ, Yun JA, Jabeen S, Jeon EK, Won HS, Ko YH, Kim SY. Prognostic significance of TMEM16A, PPFIA1, and FADD expression in invasive ductal carcinoma of the breast. World J Surg Oncol. 2014;12:137.

22. Alfarsi LH, El Ansari R, Craze ML, Masisi BK, Ellis IO, Rakha EA, Green AR. PPFIA1 expression associates with poor response to endocrine treatment in luminal breast cancer. BMC Cancer. 2020;20:425.

23. Astro V, Chiaretti S, Magistrati E, Fivaz M, de Curtis I. Liprin-a1, ERC1 and LL5 define polarized and dynamic structures that are implicated in cell migration. J Cell Sci. 2014;127:3862-76.

24. Hsu HC, Lapke N, Chen SJ, Lu YJ, Jhou RS, Yeh CY, Tsai WS, Hung HY, Hsieh JC, Yang TS, Thiam TK, You JF. PTPRT and PTPRD Deleterious Mutations and Deletion Predict Bevacizumab Resistance in Metastatic Colorectal Cancer Patients. Cancers (Basel). 2018;10.

25. Ren H, Xu Z, Guo W, Deng Z, Yu X. Rab3IP interacts with SSX2 and enhances the invasiveness of gastric cancer cells. Biochem Biophys Res Commun. 2018;503:2563-8.

26. Xu D, Wang Y, Liu X, Zhou K, Wu J, Chen J, Chen C, Chen L, Zheng J. Development and clinical validation of a novel 9-gene prognostic model based on multi-omics in pancreatic adenocarcinoma. Pharmacol Res. 2020;164:105370.

27. Anand S, Khan MA, Khushman M, Dasgupta S, Singh S, Singh AP. Comprehensive Analysis of Expression, Clinicopathological Association and Potential Prognostic Significance of RABs in Pancreatic Cancer. Int J Mol Sci. 2020;21.

28. Guo W, Chen Z, Chen Z, Yu J, Liu H, Li T, Lin T, Chen H, Zhao M, Li G, Hu Y. Promotion of Cell Proliferation through Inhibition of Cell Autophagy Signalling Pathway by Rab3IP is Restrained by 
MicroRNA-532-3p in Gastric Cancer. J Cancer. 2018;9:4363-73.

29. Hur K, Cejas P, Feliu J, Moreno-Rubio J, Burgos E, Boland CR, Goel A. Hypomethylation of long interspersed nuclear element-1 (LINE-1) leads to activation of proto-oncogenes in human colorectal cancer metastasis. Gut. 2014;63:635-46.

\section{Figures}

A

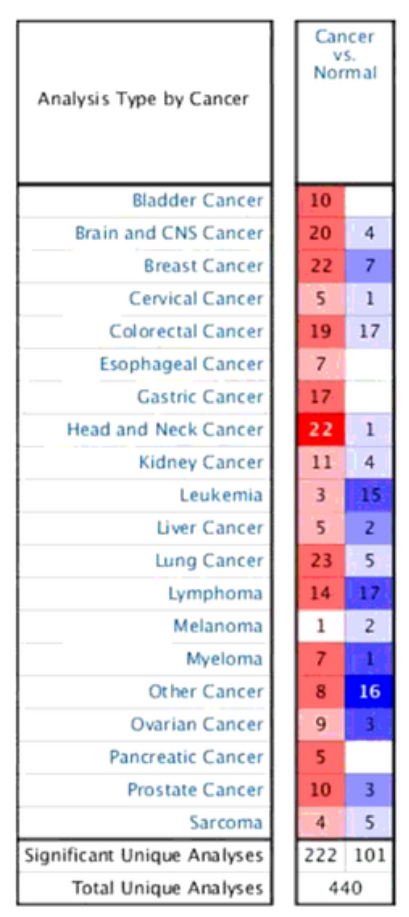

B

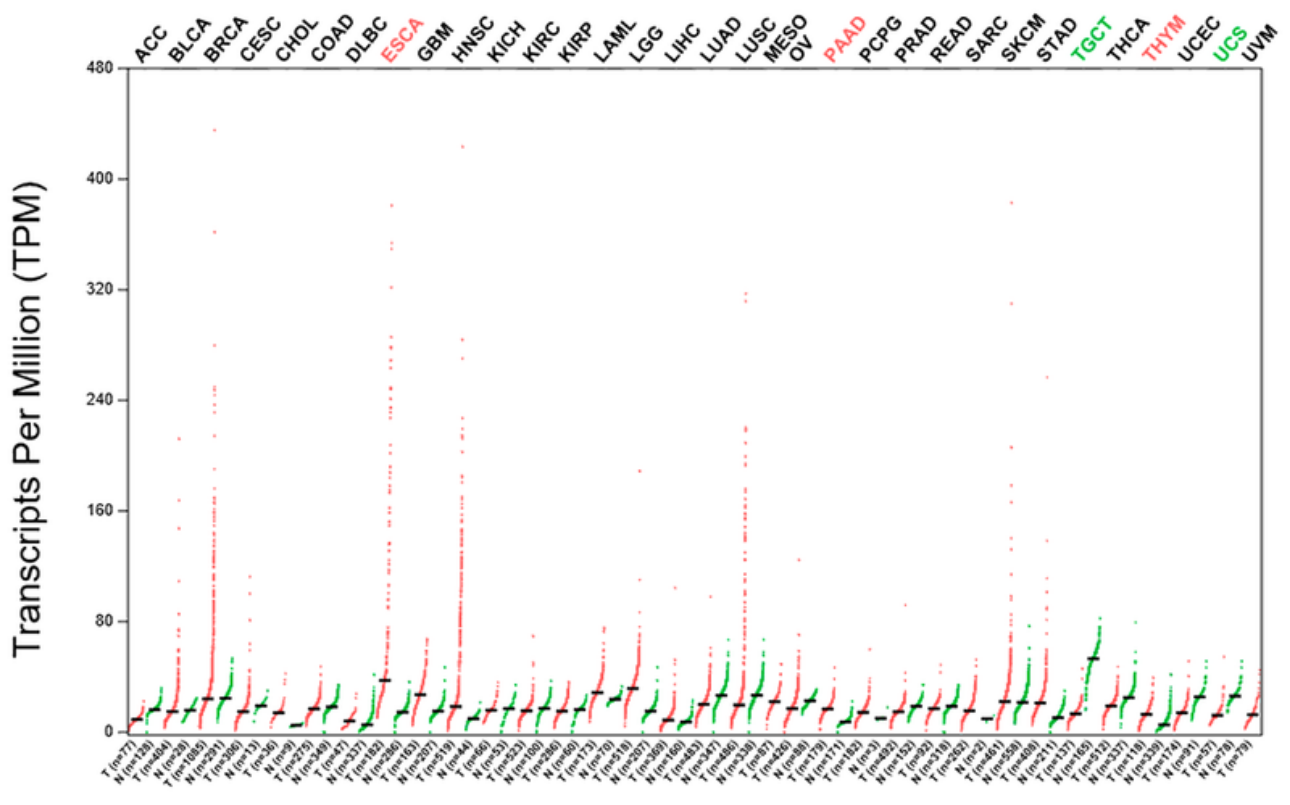

\section{Figure 1}

Overview of PPFIA1 mRNA expression levels in different types of tumors. (A) The PPFIA1 mRNA expression in different tumor tissues compared with normal controls was analyzed using the Oncomine database. (B) The PPFIA1 expression profile of tumor tissues and paired normal tissues was analyzed using the GEPIA website. Abbreviations: PPFIA1, PTPRF interacting protein alpha 1; GEPIA, Gene Expression Profiling Interactive Analysis. 
A

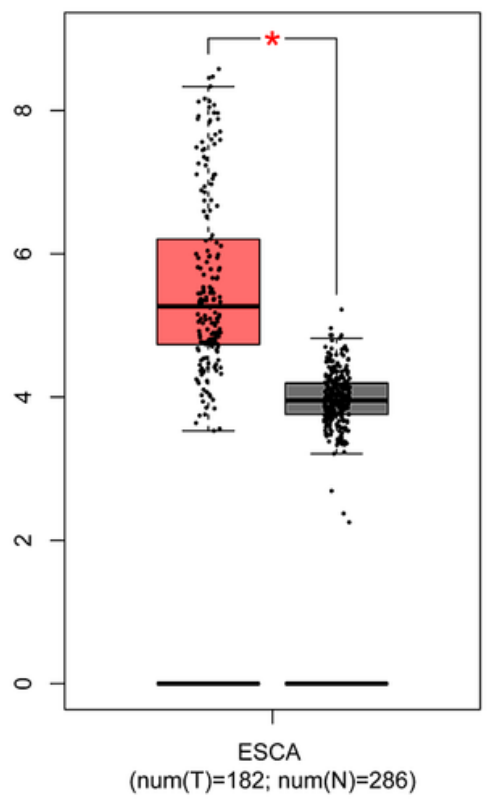

$\mathrm{F}$

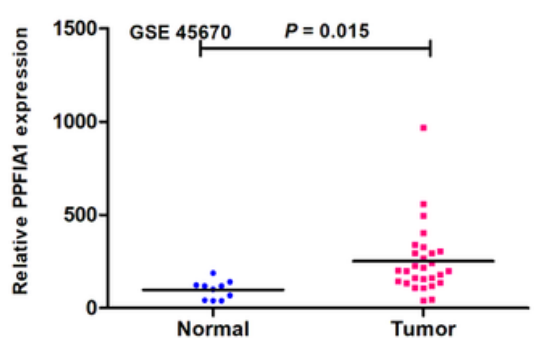

B

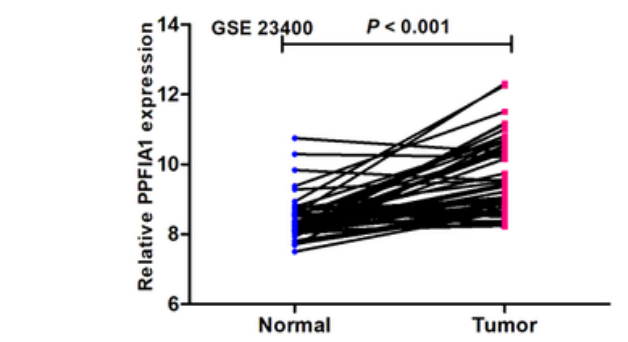

$\mathrm{D}$

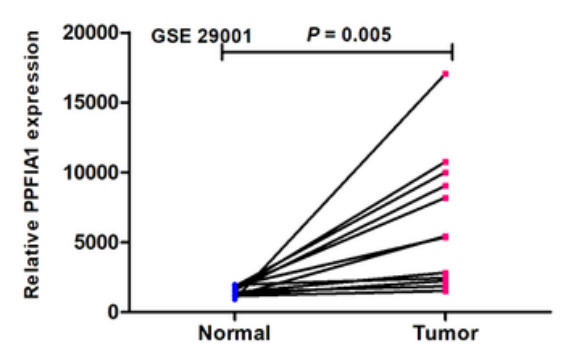

G

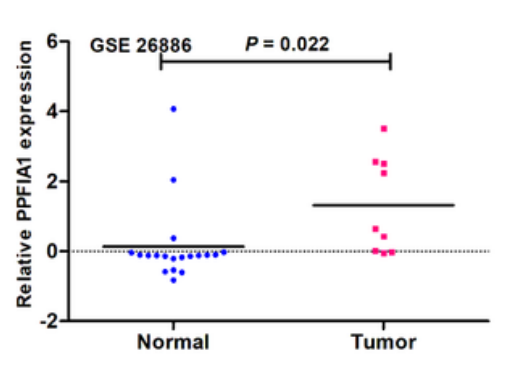

C

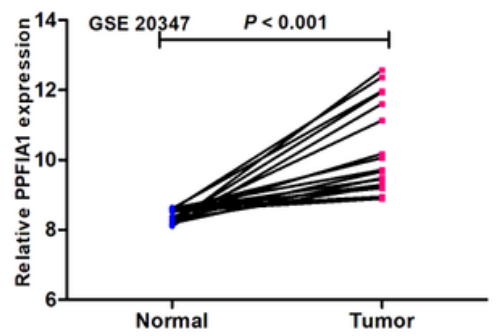

E

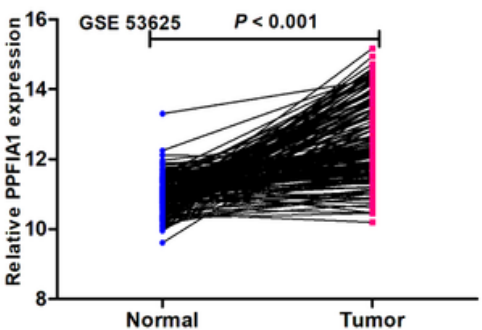

$\mathrm{H}$

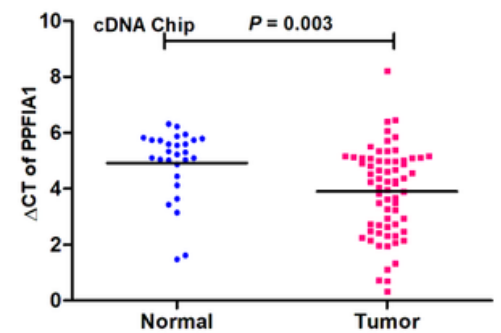

Figure 2

The expression of PPFIA1 mRNA in ESCC patients. PPFIA1 mRNA expression in ESCC tissues versus normal tissues was analyzed using the GEPIA datasets (A); PPFIA1 mRNA was highly expressed in ESCC tissues compared to noncancerous tissues in the GSE23400 (B), GSE20347 (C), GSE29001 (D), GSE53625 (E), GSE45670 (F) and GSE26886 (G) datasets; PPFIA1 mRNA expression was determined in 67 tumor tissues and 28 normal tissues (cDNA array) using qRT-PCR analysis $(\mathrm{H}) .{ }^{*} \mathrm{P}<0.05$ comparison between normal and tumor tissues. Abbreviations: PPFIA1, PTPRF interacting protein alpha 1; GEPIA, Gene Expression Profiling Interactive Analysis; ESCC, esophageal squamous cell carcinoma. 


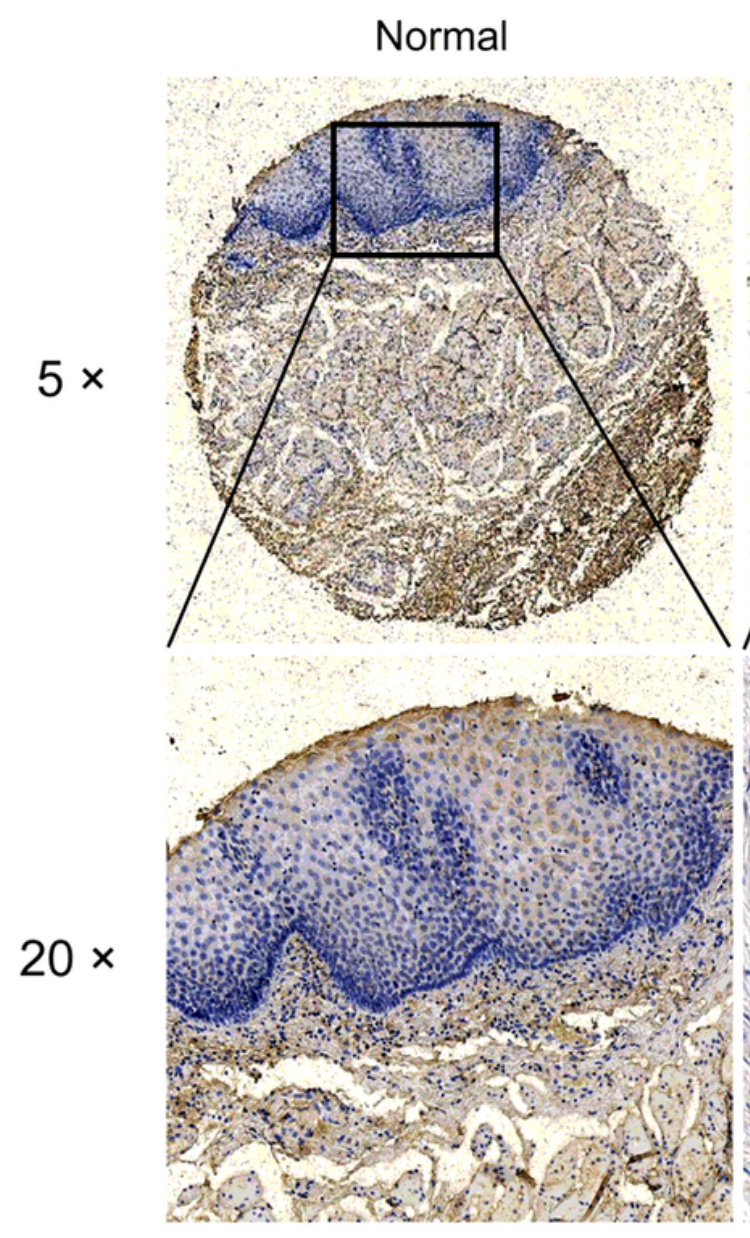

Negative
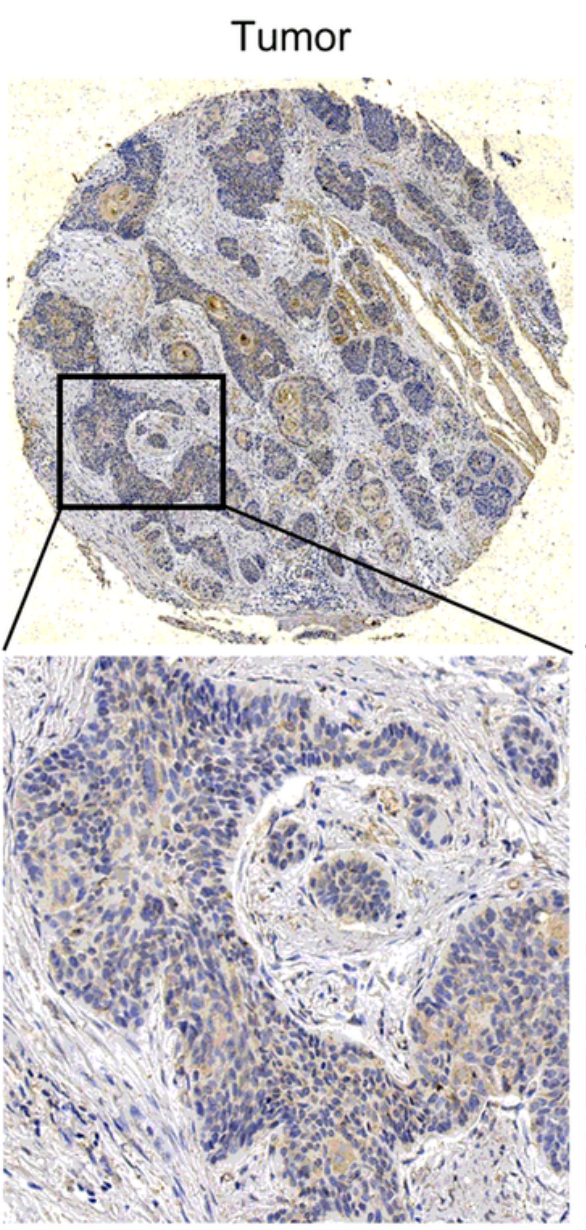

Low expression

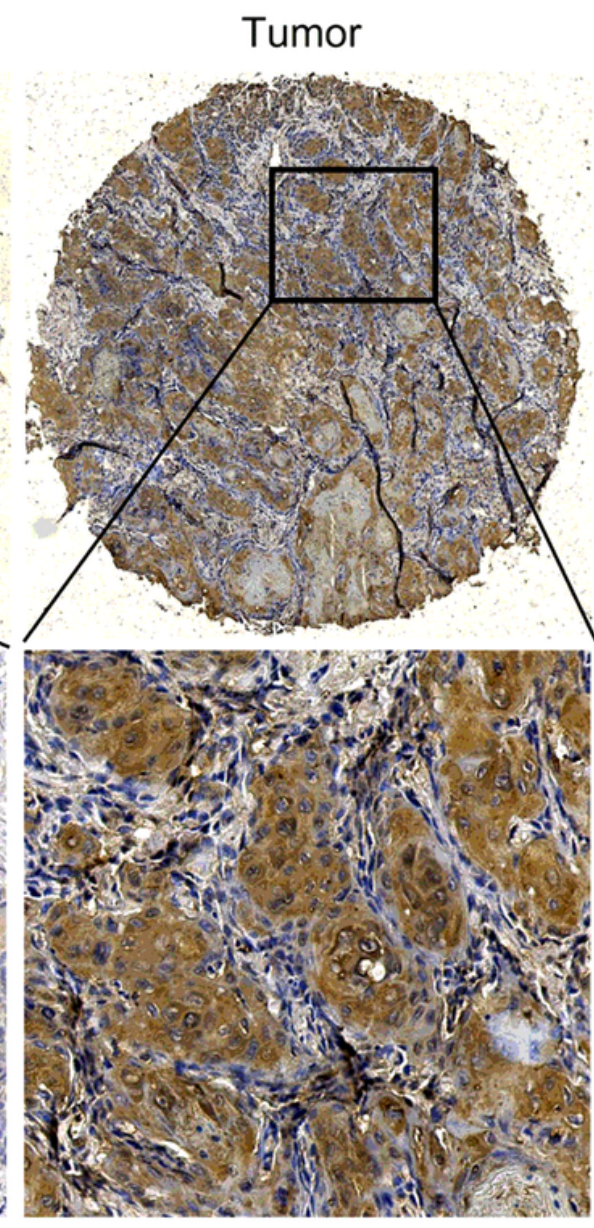

High expression

\section{Figure 3}

The expression of PPFIA1 protein in ESCC tissues was detected in a tissue microarray. (A) Negative PPFIA1 expression in sections of nonneoplastic mucosa adjacent to tumors; (B) Low PPFIA1 expression in ESCC tissue; (C) High PPFIA1 expression in ESCC tissue. Representative photographs were taken at a magnification of $40 \times$ or $200 \times$. Abbreviations: PPFIA1, PTPRF interacting protein alpha 1; ESCC, esophageal squamous cell carcinoma. 
A

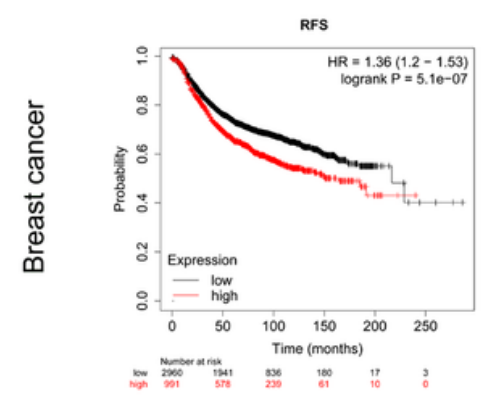

B

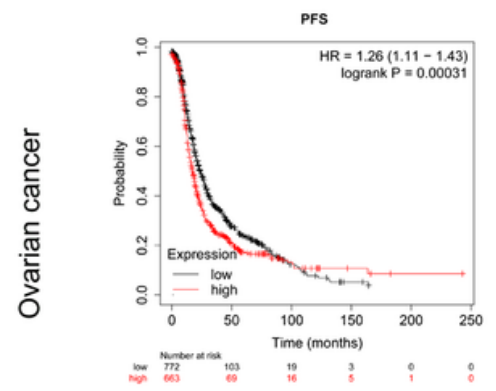

C

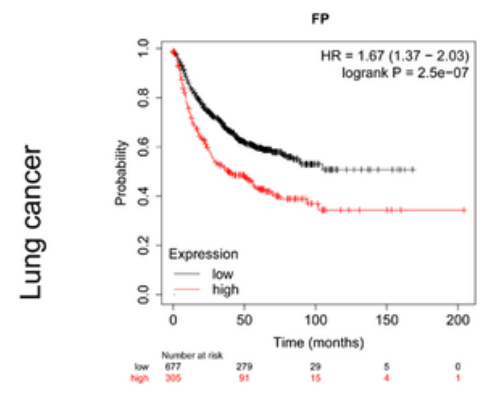

D

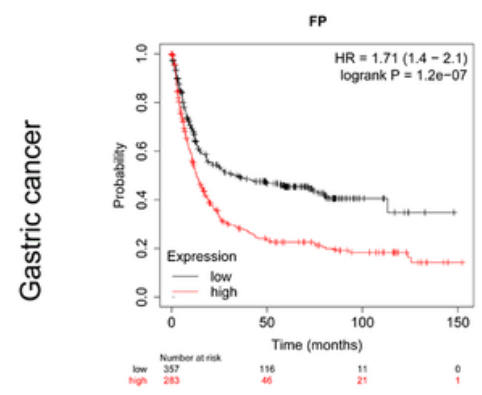

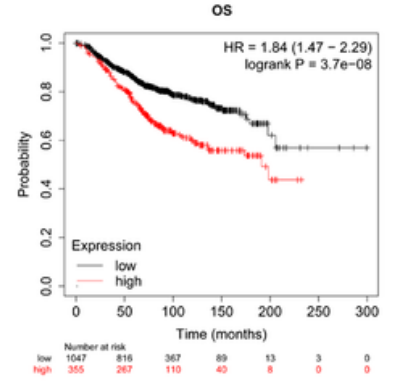
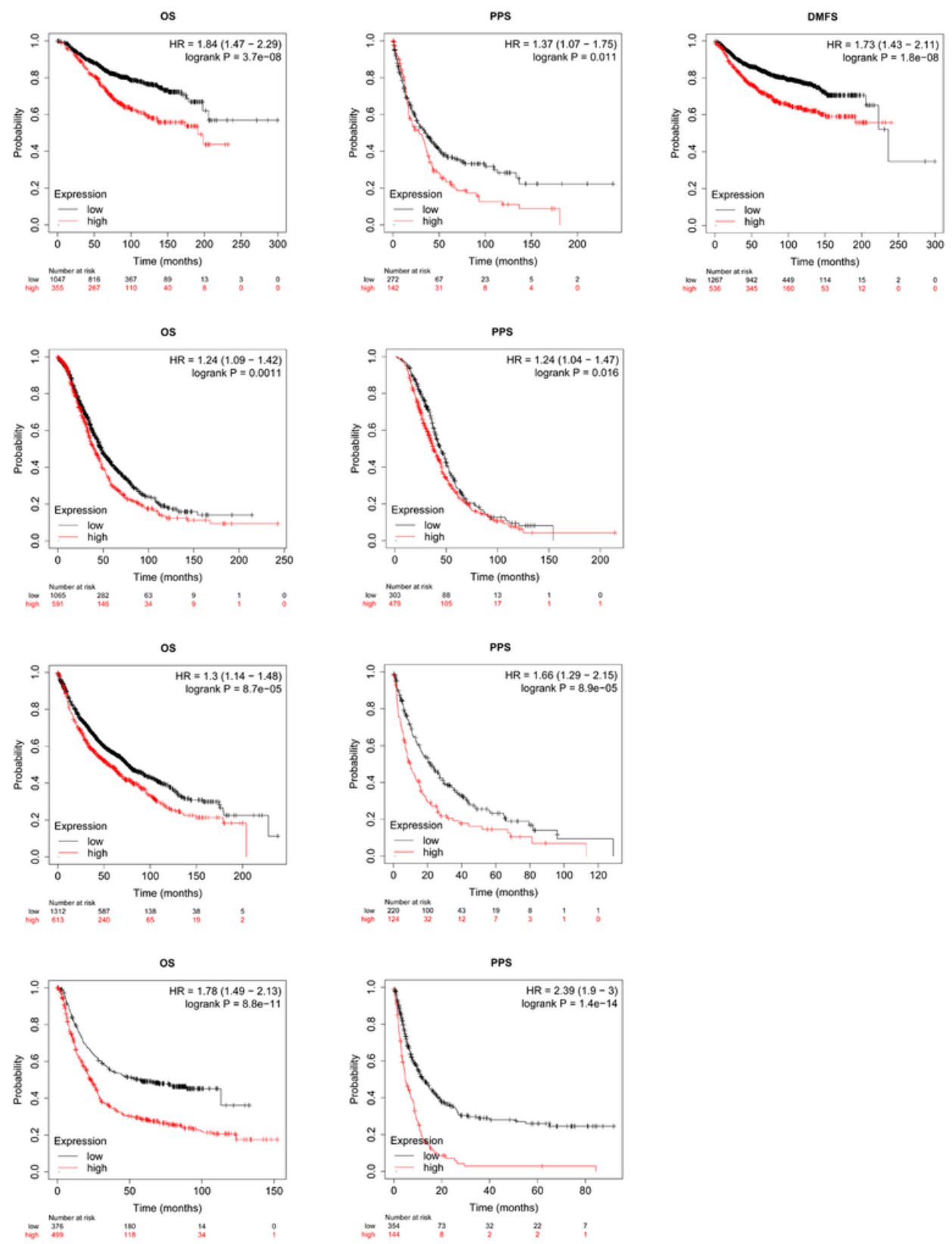

\section{Figure 4}

The correlations between PPFIA1 expression and the prognoses of patients with malignancies were analyzed using Kaplan-Meier plotter. Correlation of PPFIA1 expression with the RFS, OS, PPS, and DMFS of breast cancer patients (A); PFS, OS, and PPS of ovarian cancer patients (B); FP, OS, and PPS of lung cancer patients (C); and FP, OS, and PPS of gastric cancer patients. 

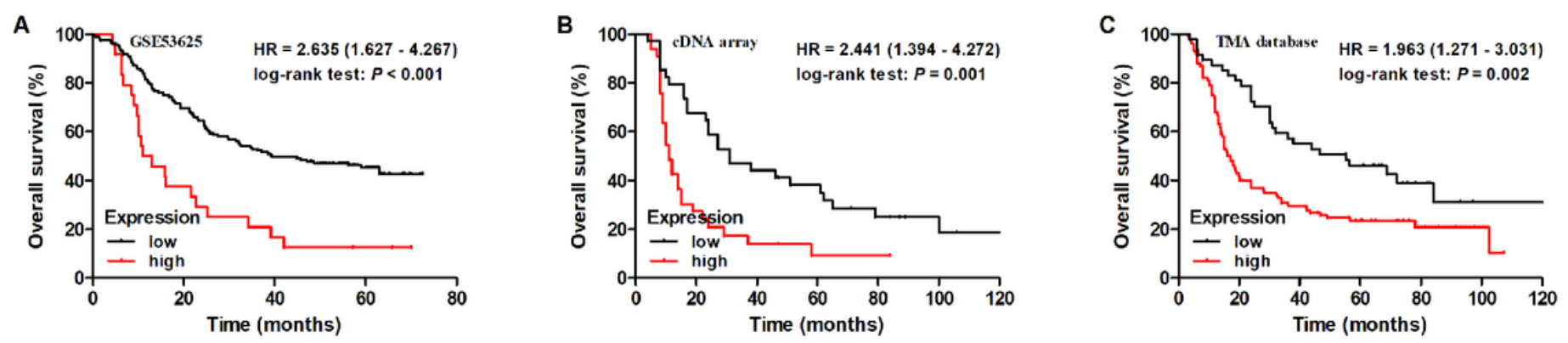

Figure 5

The association of PPFIA1 expression with the OS of ESCC patients. (A) Kaplan-Meier curve of PPFIA1 mRNA expression stratification in the GSE53625 dataset; (B) Kaplan-Meier curve of PPFIA1 mRNA expression stratification in cDNA array; (C) Kaplan-Meier curve of PPFIA1 protein expression stratification in the TMA dataset. Abbreviations: PPFIA1, PTPRF interacting protein alpha 1; ESCC, esophageal squamous cell carcinoma; TMA, tissue microarray. 
A

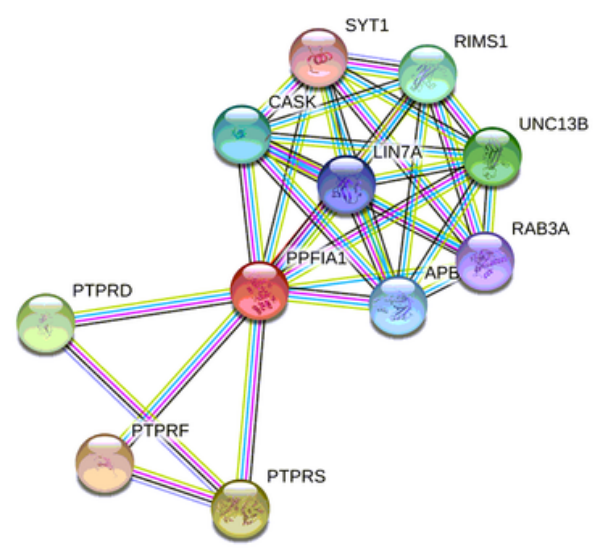

$\mathrm{F}$
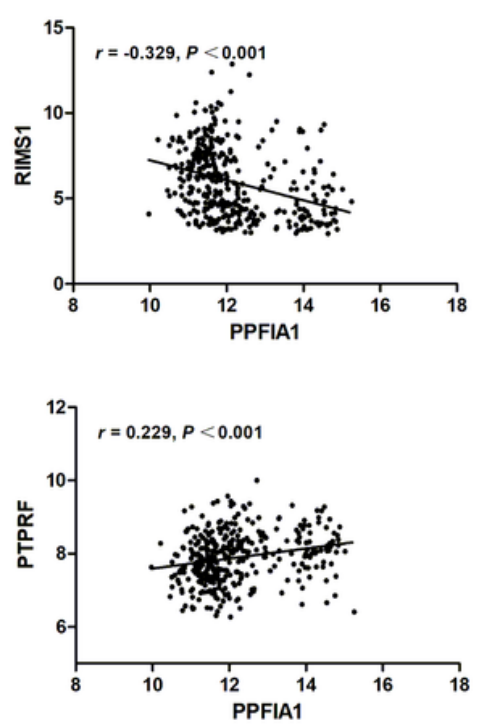

B
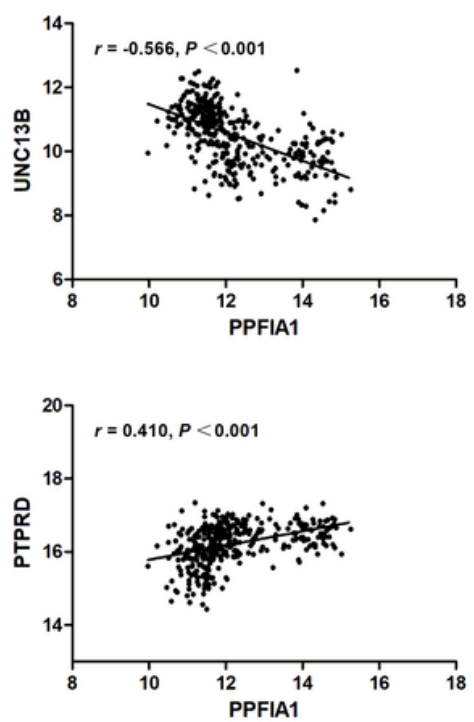

G

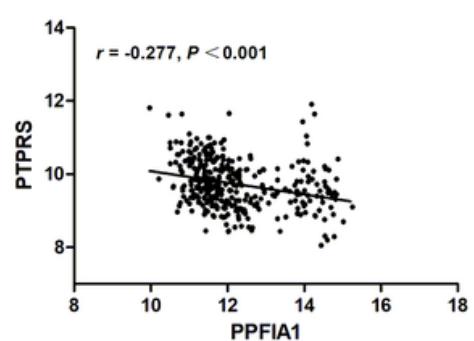

$\mathrm{J}$

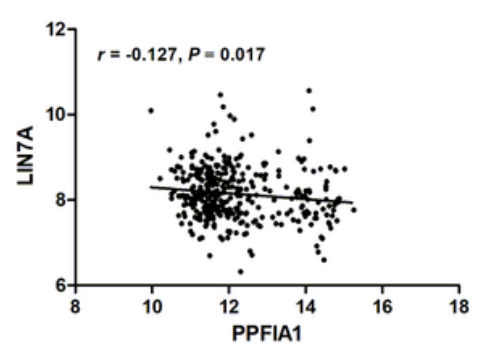

C

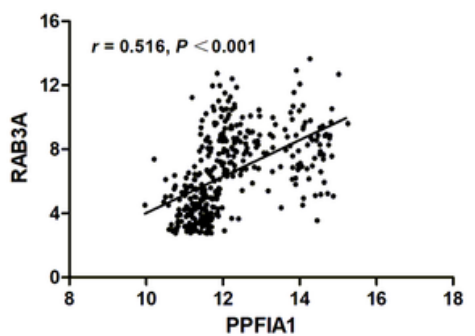

E

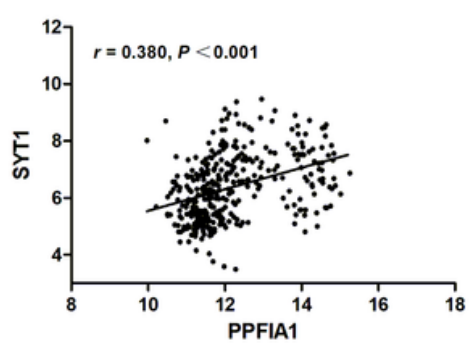

$\mathrm{H}$

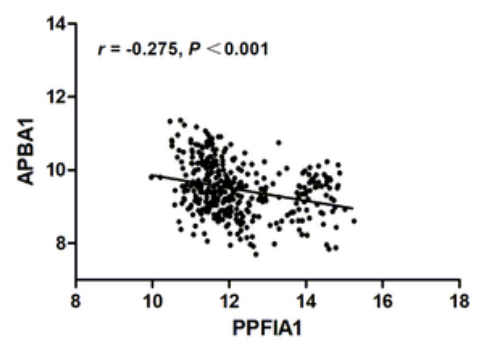

$\mathrm{K}$

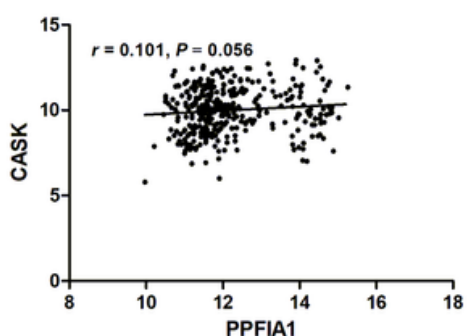

Figure 6

Analysis of PPFIA1-related proteins based on the PPI network. (A) Annotations of the genes that were associated with PPFIA1 using the STRING database. The associations of PPFIA1 expression with UNC13B (B), RAB3A (C), PTPRD (D), SYT1 (E), RIMS1 (F), PTPRS (G), APBA1 (H), PTPRF (I), LIN7A (J), and CASK (K) expression were assessed by Pearson's correlation analysis in the GSE53625 dataset. Abbreviations: PPFIA1, PTPRF interacting protein alpha 1; PPI, protein-protein interaction.

\section{Supplementary Files}

This is a list of supplementary files associated with this preprint. Click to download.

- TableS1.docx

- Tables2.docx 